\title{
Analysis of the Validity of Kuznets Curve of Energy Intensity among D-8 Countries: Panel-ARDL Approach
}

\author{
Parto Fazli ${ }^{1, a^{*}}$, Ebrahim Abbasi ${ }^{2, b}$ \\ ${ }^{1,2}$ Department of Economics, Islamic Azad University (Central Unit), Tehran, Iran \\ aparto.fazli@yahoo.com, bebr.abasi@iauct.ac.ir
}

Keywords: Energy intensity, Economic growth, Kuznets curve, D-8 group.

\begin{abstract}
The objective of the study is to test experimentally the Kuznets curve of energy intensity in selected developing countries (Iran, Turkey, Malaysia, Pakistan, Egypt, Bangladesh, Indonesia and Nigeria) with the focus of D-8 countries during 1990-2014. According to the results, and by using the static and dynamic estimators and the Panel- ARDL model, the Kuznets curve was accepted for energy intensity and the per capita income threshold was estimated $\$ 3931.25$. The urbanization rate and the degree of industrialization have a positive and significant effect on the GDP of consuming energy of D-8 countries in the long term. The most important policy recommendations were discussed for policy-makers and researchers.
\end{abstract}

JEL classification: Q43, C23, O13.

\section{Introduction}

One of the macro-energy variables is energy intensity which is followed in order to realize the green economy and its footprint. The energy intensity is the ratio of energy consumption to the gross domestic product, in which energy consumption enters the energy intensity equation either as the "final energy consumption" or as the "primarily supply energy". On the other hand, the reality shows that the developing countries are reluctant to encounter with environmental agreements such as Kyoto, Copenhagen and Paris (COP21) because of disagree with any convention that causes growth and economic developing restriction due to macro-domestic structural problems. Because of this, the importance of decreasing energy intensity in developing countries is doubled, because decreasing energy intensity which is produced as the result of production's technological development, and modification of the consumption pattern are not only consistent with environmental conventions and reducing greenhouse gases, but they also lead to the economic growth. The analysis of this indicator shows that industrialized countries have reduced their energy consumption by increasing the energy consumption efficiency since 1970, while the manufacturing sector of these countries have not been damaged. Therefore, according to endogenous growth models and learning effects, it is expected that the process of energy intensity in developing countries will be similar to the process of industrialized countries' energy consumption intensity, which developing countries are required to create some institutional and technical infrastructure on their own behalf. Also, by considering the complexity of the energy intensity indicator, this indicator can be used to promote the objectives of environmental conventions [1]. In spite of the additive global process of energy per capita consumption, the intensity of primary energy supply has declined globally, and it has decreased from 7.58 million Jules per dollar in 1990 (equal to purchasing power to the ratio of constant price of 2011) ${ }^{1}$, and to 5.36 million Jules per dollar in 2014 (equal to the ratio of purchasing power to constant price of 2011) [2]. Undoubtedly, global economic growth (and the growth miracle in some countries, including China), global intergenerational change in favor of the services sector, using renewable energy sources, the application of new management methods, the advancement of information and communication technologies (ICT) and increment of the energy efficiency have been globally effective on reducing energy intensity. 
There are many empirical studies have been conducted concerning the effective factors on energy degradation and its decomposition., they are; Mulder et al. (2014), Huang et al. (2017), Adom (2015), Burnett et al. (2017), Bilgili et al. (2017), Choi et al. (2017) [3,4,5,6, 7, 8]. The results of empirical studies depend on the period of the research, the statistical society and the estimation technique and methodology of research. One of the important variables that influences on the state of consuming energy intensity of countries is the position of those countries in the path of economic growth and development. Rostow (1990) categorizes the stages of economic growth and development into five stages: the traditional society, the preconditions for the take-off, the drive to maturity and the age of high mass consumption [9]. At each of these stages, a variety of businesses can have different effect on the intensity of energy due to their nature. For example, at the traditional community stage, most of the activities are based on traditional agriculture and trade; therefore, the levels of energy intensity tend to be lower at this stage. At the maturity stage, industry and manufacturing are the main actors, so the energy intensity is higher at this stage. On the contrary, at the mass consumption stage, services constitute an important part of production, and per capita output is significantly increased. The behavior of energy intensity at the mass consumption and post-disinfection stages requires testing and evaluating. It is possible that energy saver activities can be expanded and citizens are asked to learn how to use energy efficiently. So, it is possible that the rebound (reflective) effect can be activated and energy intensity becomes increase due to the use of energy consumption for unproductive activities. According to the abovementioned cases, we attempt to answer this ambiguity by using panel data and Kuznets curve techniques. According to the Kuznets' curve, energy intensity increases at the early stages of economic growth, but the intensity of energy has a decreasing process or its increasing rate decreases after the threshold of per capita income [10]. Investigated countries are considered as the D-8 Group. D-8 Group ${ }^{2}$ is the regional convention designed to make strong economic relationships among the developing countries of the Islamic world and to strengthen the influence of these countries on global markets and to establish a dialogue with industrial countries. The members of the D-8 Group are Indonesia, Iran, Bangladesh, Pakistan, Turkey, Malaysia, Egypt and Nigeria [11].

This study is organized in five sections following the introduction. Section 2 describes literature review on energy intensity briefly; Section 3 introduces the underlying research method. In Section 4 we show descriptive statistics, diagnostic tests and estimation of the empirical model. Section 5 concludes.

\section{Literature Review}

According to the energy economics literature, the intensity of energy is influenced by two factors: energy consumption and the other one is the amount of production, formulated as:

$$
\mathrm{EI}_{\mathrm{t}}=\frac{\mathrm{ED}_{\mathrm{t}}}{\mathrm{GDP}_{\mathrm{t}}}
$$

where EI is the intensity of energy, ED is the consumption (final or primary) of energy and GDP is gross domestic product. According to the methodology of decomposition ${ }^{3}$, the change in energy intensity can also be divided into two parts; "Efficiency Effect" and "Structural Effect". Efficiency indicates the change in energy efficiency within each sector so that the economic structure is stable. The structural effect also reflects the change in energy intensity due to changes in the overall structure of the economy and the economic infrastructure [12]. Therefore, due to the difference in the efficiency and structural effect among countries, it is necessary to be cautious when comparing energy intensity among countries. Also, energy intensity cannot be a complete proxy for technical energy efficiency, as some non-core factors, such as climate and area, effect on the energy intensity [2].

\footnotetext{
${ }^{2}$ Developing-8, Accessible from: http://www.developing8.org

${ }^{3}$ Decomposition analysis
} 
Further, the intensity of energy can reflect standard public characteristics or a lifestyle in an economy. Countries that experience a higher standard of living style and have a higher level of welfare also use more energy consumer products and therefore can have higher levels of energy and higher energy intensity. Also, it is possible to change the mental pattern of citizens by increasing economic prosperity. Increasing demand for efficient and standard products, standard consumption of energy, increasing of awareness and environmental sensitivity can be achieved by increasing per capita income [13].

In general, the parameters affecting energy intensity are divided into three groups: technical, economical, and cultural. The study of the energy intensity process in developed countries suggests that energy intensity depends on the level of economic development and the degree of development. In the 1990, observing evidences based on a link between environmental destruction and per capita income indicators the word "Kuznets curve" was used in studies related to pollutant and environmental quality issues and known as the "Environmental Kuznets Curve (EKC)". The hypothesis states that this relationship is hunch shaped (reversed $U$ ). This means that environmental degradation increases at the early stages of economic growth, and environmental damage will decrease by economic and social conditions improvement and growth of per capita income. The peak of this curve is called "immaterial growth". This means that since the peak of the curve, the economy is slowing down the use of materials and energy in the production process [10]. In fact, the message of this hypothesis is clear; "the economic growth is both the reason of pollution and its treatment". Therefore, the arrival of the economy to the stage of immaterial growth indicates that economic growth will become a cure for environmental problems.

Environmental Kuznets curve form for energy intensity can also provide significant results in terms of sustainable development and economic growth. In this sense, energy intensity has a direct and positive relationship with economic development, but since a per capita income level and due to technological and technological advances and an inter-sectional shift in the economy, the relationship between these two variables is reversed. Also, by increasing the real per capita income and economic well-being of citizens, economic agents learn how to use energy efficiently, which causes reducing energy consumption in the economy. In contrast, economic prosperity may lead to develop plethora lifestyles in society, which will also increase the energy consumption in nonproductive sectors and, as a result, increase energy consumption in the economy. Fig. 1 shows the Kuznets' curve concept of energy intensity. As it is seen, the economy will have structural break at the threshold point and after that. These structural changes may emerge in many ways, for example, the transformation in a variety of industrial products and the movement from one economic activity to another (increasing the share of services unit in the GDP) and changing the production method from the energy consumer industry to the energy saver industries. Another type of structural change may take place with the substitution between fuels. The best example in this regard is the dramatic growth in the use of combined gas turbines for power generation, which not only has environmental benefits, but it also has economical fuel benefits.

On the other hand, there are some specific factors affecting the energy intensity of some countries with natural energy resources. These easy and inexpensive accesses to the energy carriers connected to the high energy intensity in these countries. In these countries, industries such as petrochemicals, paper, base materials has expanded; therefore, the high energy intensity in these countries cannot be necessarily linked to the inefficiency of their energy consumption. It is worth noting that the high loss of energy cannot be ignored due to the cheapness of energy carriers in naturally resourceful countries [13]. 


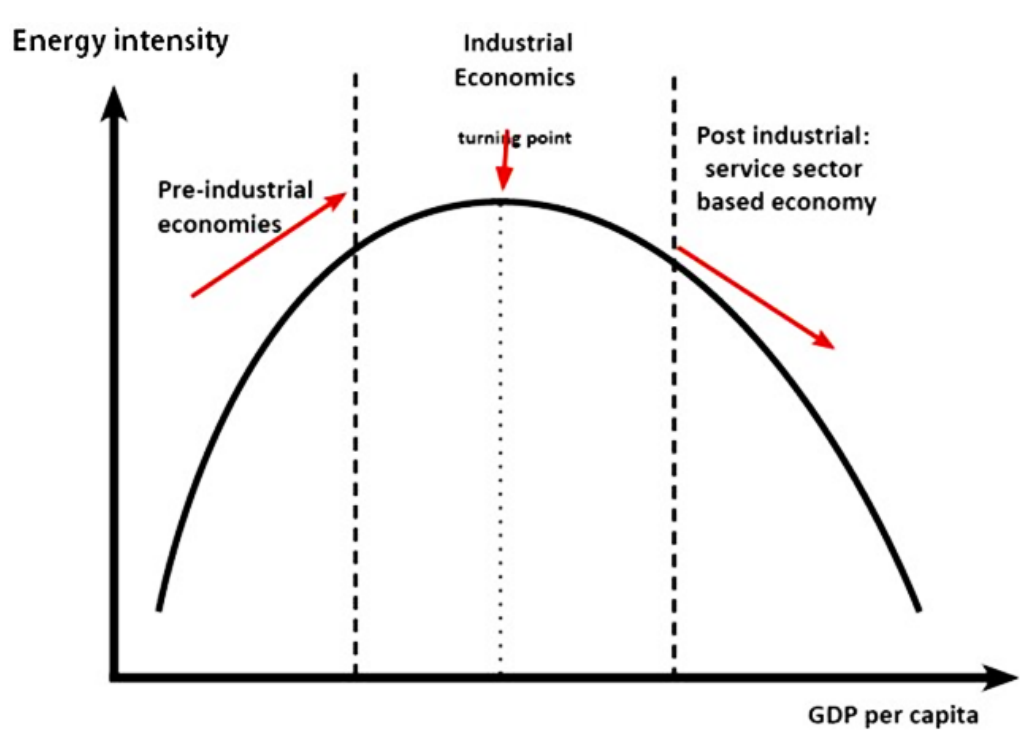

Figure 1. Kuznets curve of energy intensity

Table 1 shows a summary of the characteristics of empirical studies. As mentioned, the results of empirical studies often depend on the methodology of the considered research and statistical society. In most studies, the degree of industrialization has had a positive and significant impact on energy intensity, indicating a structural effect.

Table 1. A summary of the characteristics of the most important empirical studies

\begin{tabular}{|c|c|c|c|}
\hline Authors & Panels & $\begin{array}{c}\text { Estimation } \\
\text { method }\end{array}$ & Results' summary \\
\hline $\begin{array}{c}\text { H.Yu, 2012 } \\
{[14]}\end{array}$ & $\begin{array}{c}30 \text { provinces } \\
\text { of China }\end{array}$ & $\begin{array}{c}\text { Spatial panel } \\
\text { data }\end{array}$ & $\begin{array}{l}\text { A negative and significant effect on per capita income, } \\
\text { transportation infrastructure, degree of marketing and } \\
\text { scientific and technological institutions on energy intensity. } \\
\text { Positive and significant impact of dirty industries and coal } \\
\text { consumption on energy consumption intensity. Positive spatial } \\
\text { self-correlation of energy intensity and spatial overflow of } \\
\text { energy intensity shocks/Absolute and conditional convergence } \\
\text { of energy intensity. }\end{array}$ \\
\hline $\begin{array}{l}\text { Sadorsky, } \\
2013 \text { [15] }\end{array}$ & $\begin{array}{c}76 \text { developing } \\
\text { countries } \\
{[1980-2010]}\end{array}$ & \begin{tabular}{|c|} 
Heterogeneous \\
panel estimators \\
include MG, \\
CCEMG and \\
AMG \\
\end{tabular} & $\begin{array}{l}\text { Negative and significant effect of per capita income on energy } \\
\text { intensity, positive and significant effect of industrialization on } \\
\text { energy intensity, uncertain relation in terms of sign between } \\
\text { urbanization and energy intensity. }\end{array}$ \\
\hline $\begin{array}{l}\text { P.K. Adom, } \\
2015 \text { [5] }\end{array}$ & $\begin{array}{l}\text { South Africa- } \\
(1970-2011)\end{array}$ & $\begin{array}{l}\text { Time series } \\
\text { methods and } \\
\text { FMOLS } \\
\text { estimator }\end{array}$ & $\begin{array}{l}\text { - The negative and significant effect of oil prices on energy } \\
\text { intensity } \\
\text { - The positive and significant impact of industrialization on } \\
\text { energy intensity. } \\
\text { - The negative effect of economic integration index on energy } \\
\text { intensity. }\end{array}$ \\
\hline $\begin{array}{c}\text { Yan, } 2015 \\
{[16]}\end{array}$ & $\begin{array}{l}30 \text { provinces } \\
\text { of China } \\
(2000-2012)\end{array}$ & \begin{tabular}{c|} 
regression \\
Driscoll- Kraay
\end{tabular} & $\begin{array}{l}\text { - The positive impact of urbanization on the intensity of } \\
\text { energy consumption, the intensity of the electricity } \\
\text { consumption, the intensity of the use of coal. } \\
\text { - The positive and significant impact of industrialization on } \\
\text { the intensity of energy consumption. }\end{array}$ \\
\hline $\begin{array}{c}\text { Duran, et al. } \\
2015 \text { [17] }\end{array}$ & $\begin{array}{l}\text { Chile's } \\
\text { industries } \\
(1990-1980)\end{array}$ & $\begin{array}{l}\text { LMDI } \\
\text { decomposition } \\
\text { and index } \\
\text { methodology }\end{array}$ & $\begin{array}{l}\text { The intensity of energy consumption in Chile's industries has } \\
\text { increased despite the constant consumption of energy. } \\
\text { - Each subdivision of industry, has different process and } \\
\text { pattern of energy intensity and energy consumption, and have } \\
\text { to be applied for sub-sectors and different energy management } \\
\text { policies. }\end{array}$ \\
\hline
\end{tabular}




\section{Research Method}

In this research, the research model is conducted in panel data framework. Using this model has several advantages that include the increased efficiency of the estimated results due to the use of more diverse information and also the comprehensiveness of the analysis results due to the ability of this model to model the effects of cross-sectional data along with time series data. Therefore, the analysis results of interpreting the cross-sectional data or time series data are more complete and comprehensive [18]. Also, for panels that have more years of time (T), the dynamic estimator of Generalized Method of Moments (GMM) is not very effective, because the dynamic estimator of Generalized Method of Moments (GMM) is applicable and effective when the number of the sections is more than the time series dimension. In this research, the time dimension is much greater than the cross-sectional dimension (25 years versus 8 countries), and the dynamic mean group estimators (MG and PMG) are well suited for these situations. Equation (2) shows the verification model in the panel model framework with homogeneous slope coefficients and the equation (3) represents the verification model in the panel model framework with heterogeneous slope coefficients:

$$
\begin{aligned}
& Y_{i t}=\alpha 1_{0}+\beta 1 X 1_{i t}+\beta 2 X 2_{i t}+\beta 3 X 3_{i t}+\varepsilon_{i t} \\
& Y_{i t}=\alpha 2_{0}+\beta_{1 i} X 1_{i t}+\beta_{2 i} X 2_{i t}+\beta_{3 i} X 3_{i t}+v_{i t}
\end{aligned}
$$

In which $\mathrm{i}$ and $\mathrm{t}$ represent the cross section and time in the panel, respectively, $\mathrm{Y}$ is the dependent variable and $\mathrm{X}$ is the explanatory variable. There is a significant difference between the models with homogeneous slope coefficient $\left(\beta_{1 i}=\beta_{1}, \beta_{2 i}=\beta_{2}, \beta_{3 i}=\beta_{3}\right)$ and models with heterogeneous slope coefficients $\left(\beta_{1 i}, \beta_{2} i, \beta_{3 i}\right)$; If the hypothesis of homogeneous slope coefficients is accepted, these models can be estimated by conventional panel regression techniques such as cumulative regression (POOL), fixed and random effects (FE, RE), dynamic least squares (DOLS) and generalized systematic and differential method of moments. However, models with heterogeneous slope coefficients are estimable by mean group estimators (MG) of Pesaran and Smith (1995) [19], common correlated effects mean group estimators (CCEMG) Pesaran (2006)[20] and augmented mean group estimator (AMG). The estimation of panel models with heterogeneous slope coefficients has found a good situation in empirical work because they are more consistent with the economic realities [21,22]. All mean group estimators of a group follow two general principles: a) Estimate a special estimation for each group which is existed in the panel. b) Average the coefficients of each group in order to achieve the total coefficient of the panel. In this case, the heterogeneity of the groups (countries) is considered in the estimation and the obtained coefficients will be closer to the realities of the economy.

The dynamic form of the mean group estimators is presented in the form of the selfregression pattern with panel ARDL distributional delays ( $\left.\mathrm{p}, \mathrm{q} 1, \mathrm{q} 2, \ldots, \mathrm{q}_{\mathrm{N}}\right)$. The mathematical equation of the panel ARDL pattern by assuming the period $t=1,2,3 \ldots \mathrm{T}$, and in the form of groups $\mathrm{i}=1,2,3 \ldots \mathrm{N}$, are in the form of equation (4) [23]:

$$
Y_{i, t}=\sum_{j=1}^{p} \lambda_{i j} Y_{i, t-j}+\sum_{j=0}^{q} \delta_{i j}^{\prime} X_{i, t-j}+\mu_{i}+\varepsilon_{i, t}
$$

where $\mathrm{y}$ denotes the dependent variable (energy intensity in this research); $\mathrm{X}$ is the vector of explanatory variables (real per capita income, degree of urbanization, degree of industrialization); $\mu$ is the fixed effects and $\varepsilon$ is the disturbing component. In this study, two estimators PMG and MG are used to estimate the equation (4). The estimation method PMG is placed in a position between the MG method (where slopes and latitude from the origin are allowed to vary between countries) and the classical method of fixed effects (in which the slopes are constant and the latitude from the origins is allowed to change). In the PMG estimation method, only the long-term 
coefficients must be equal between countries (or groups), while short-term coefficients are allowed to change. The choice between estimator MG and PMG is done by Hausman test. In this research, the hypothesis of zero and vice versa for the Hausman test is as follows: H0: the long-term coefficients are homogeneous and can be combined (PMG method efficiency) and $\mathrm{H}_{1}$ : the longterm coefficients that are non-homogeneous and are not combinable (efficiency of MG estimator). The error- correction form of the PMG model is written as follows:

$$
\Delta y_{i t}=\phi_{i}\left(y_{i, t-1}-\theta_{i}^{\prime} X_{i t}\right)+\sum_{j=1}^{p-1} \lambda_{i j}^{*} \Delta y_{i, t-1}+\sum_{j=0}^{q-1} \delta_{i j}^{\prime}{ }^{*} \Delta X_{i, t-j}+\mu_{i}+\epsilon_{i t}
$$

The parameter $\phi_{i}$ is the error-correcting speed of adjustment term. If $\phi_{i}=0$, then there would be no evidence for a long-run relationship. This parameter is expected to significantly negative under the prior assumption that the variables show a return to a long-run equilibrium. Of particular importance is the vector $\theta_{i}^{\prime}$, which contains the long-run relationships between the variables [24].

\section{Result and Discussion}

\subsection{Descriptive statistics}

The statistical sample of this study is a sample of developed countries comprising 8 members of the D-8 (Iran, Turkey, Malaysia, Pakistan, Egypt, Bangladesh, Indonesia and Nigeria) during 1990-2014. Table 2 summarizes the most important descriptive statistics of the energy intensity of the studied countries.

Table 2. A summary of descriptive statistics of energy intensity (Million Jules per Dollar equal to purchase Power 2011) - 1990-2014

\begin{tabular}{|l|c|c|c|c|}
\hline & & & & \\
\hline Iran & 6.51 & 0.72 & 5.00 & 7.69 \\
\hline Turkey & 3.70 & 0.12 & 3.43 & 3.87 \\
\hline Malaysia & 5.32 & 0.28 & 4.80 & 5.77 \\
\hline Nigeria & 8.63 & 1.92 & 5.64 & 10.48 \\
\hline Bangladesh & 3.56 & 0.21 & 3.13 & 3.90 \\
\hline Indonesia & 4.63 & 0.47 & 3.70 & 5.31 \\
\hline Egypt & 3.77 & 0.22 & 3.29 & 4.19 \\
\hline Pakistan & 5.21 & 0.34 & 4.43 & 5.63 \\
\hline Whole(Aggregation) & 5.17 & 1.78 & 3.13 & 10.48 \\
\hline
\end{tabular}

Source: Calculated from World Bank Datasets.

According to the statistics reported in Table 2, Nigeria has the highest energy intensity, and after that Iran with an average of 6.51 million Jules per second is at the second rank. Both Nigeria and Iran have natural energy benefits and they are also members of the Organization of the Petroleum Exporting Countries (OPEC). Bangladesh has the lowest average energy intensity which is equal to 3.56 million Jules per dollar. Nigeria has the highest standard deviation of energy intensity, and given that Nigerian energy intensity process is decreasing, it can be said that energy shocks and changes are decreasing in this country. According to Fig. 3, among D-8 countries, only two countries, Iran and Malaysia, have experienced a positive growth rate of energy intensity during 1990-2014, and their energy intensity rising, while the rest of the countries have a negative growth rate of energy intensity. It is worth noting that in 2014, the energy intensity of the Iran is higher than the other D-8 countries. The growing intensity energy of Iran does not promise Iran an interesting future in terms of energy security and environmental damages. 


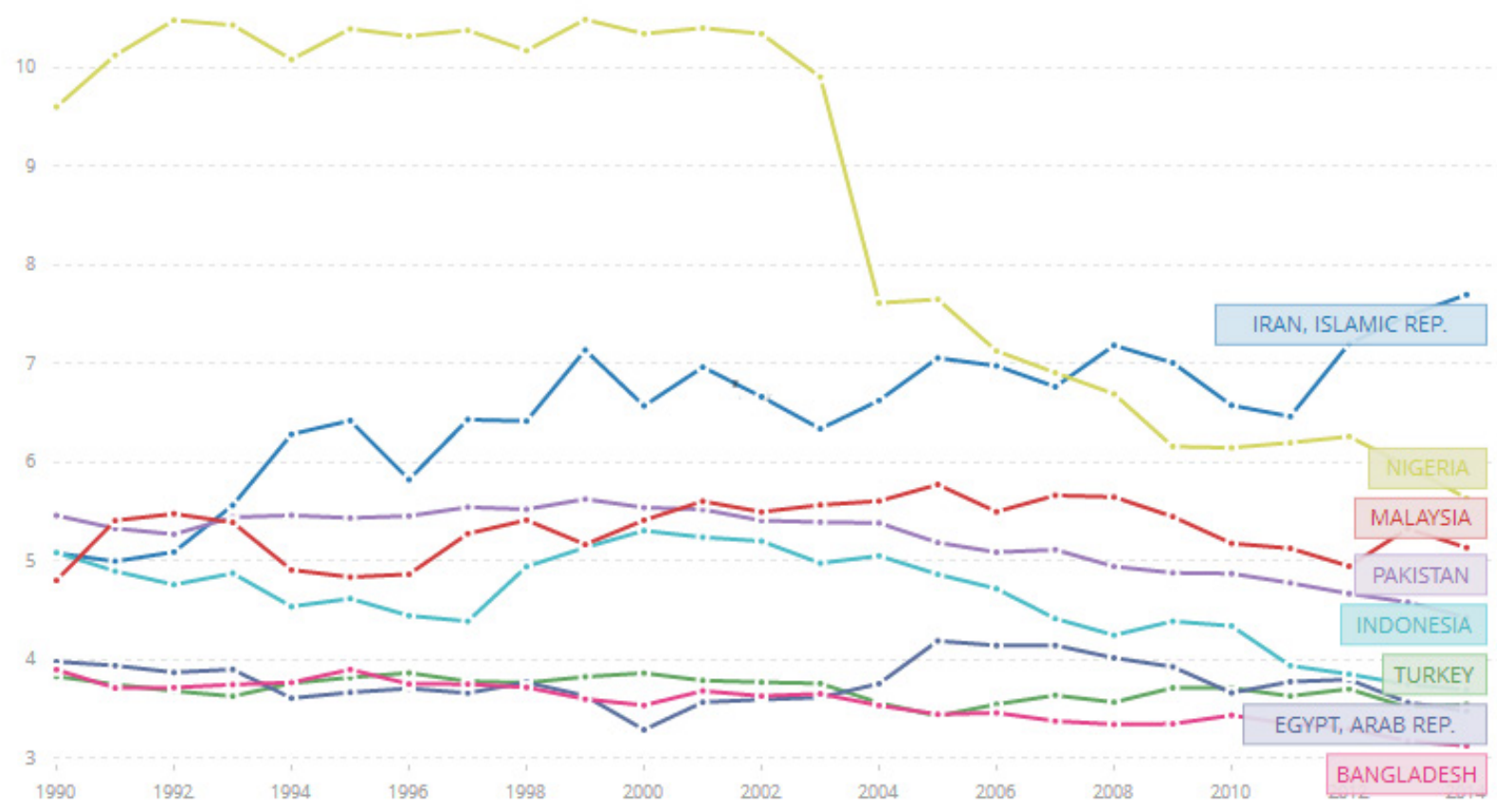

Figure 2. Primary energy intensity (MJ / \$ 2011 PPP GDP) trends of D-8 countries Source: World Bank datasets

According to Fig. 3, and in 2015, Malaysia, Turkey and Iran had the highest per capita income among the D-8 countries, respectively. The highest Gross Domestic Product (GDP) is also related to Indonesia, Turkey and Iran. Table 3 shows the definitions of the research variables.

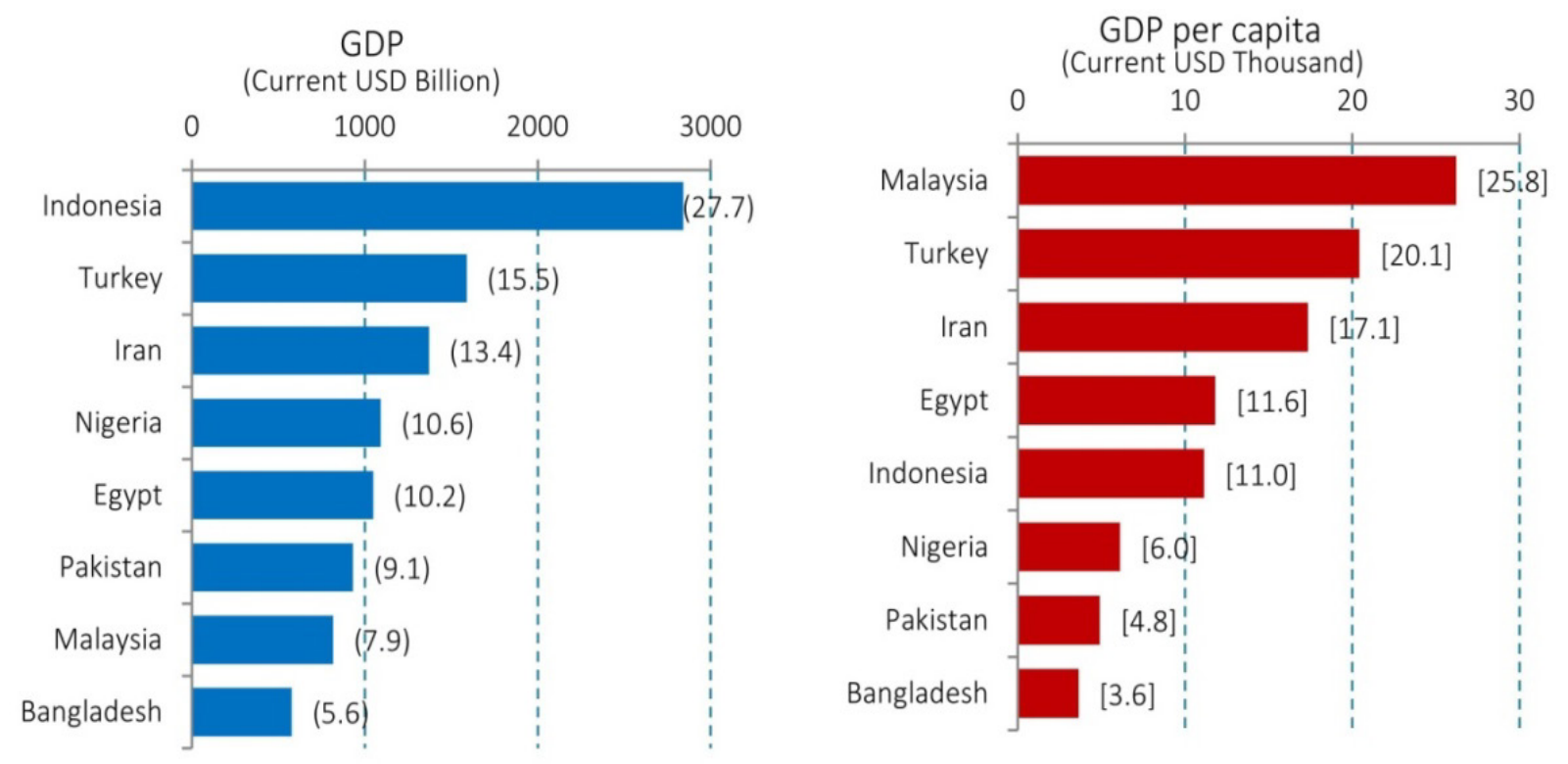

Figure 3. D8 Countries by GDP and GDP per capita (2015). Source: D-8 Organization for Economic Cooperation (http://www.developing8.org) 
Table 3. Definition of variables

\begin{tabular}{|c|l|c|}
\hline Symbol & \multicolumn{1}{|c|}{ Definition } & Unit \\
\hline EI & $\begin{array}{l}\text { Dividing total primary energy supply over gross domestic product } \\
\text { measured in constant 2011 US dollars at purchasing power parity. }\end{array}$ & $\begin{array}{c}\text { MJ / \$ 2011 PPP } \\
\text { GDP }\end{array}$ \\
\hline Y & GDP per capita, PPP & $\begin{array}{c}\text { Constant 2011 } \\
\text { international \$) }\end{array}$ \\
\hline U & Urban population (\% of total) & $\%$ \\
\hline D & Industry, value added (\% of GDP) & $\%$ \\
\hline
\end{tabular}

\subsection{Diagnostic tests}

In this section, diagnostic tests are panel unit root tests, panel integration and cross-sectional correlation tests. The implementation of this test will help us to determine the model and how to estimate it. In this research, Levin, Lin and Chu unit root test (LLC) [25] and Im-Pesaran-Shin (IPS) [26] test were used for completeness on other root tests of the panel unit, and better and more accurate results and its results are reported. Levine, Lin and Chu (LLC) test examines the unit root test in terms of the contributed cross-sectional effects and Im-Pesaran-Shin test evaluates the unit root in terms of individual cross-sectional effects.

Table 4. The results of IPS and LLC panel unit root tests

\begin{tabular}{|c|c|c|c|c|c|}
\hline Variables & \multicolumn{2}{|c|}{ LLC test } & \multicolumn{2}{|c|}{ IPS test } & \multirow{2}{*}{ I (..) } \\
\hline- & Intercept & Intercept \& Trend & Intercept & Intercept \& Trend & \\
\hline LnEI & $2.3795(0.9913)$ & $0.0996(0.5397)$ & $2.120(0.9830)$ & $0.7713(0.7798)$ & I $(1)$ \\
\hline LnY & $1.5366(0.9378)$ & $0.0406(0.5162)$ & $4.2040(0.1000)$ & $-0.5929(0.2766)$ & I $(1)$ \\
\hline LnU & $-1.2559(0.1046)$ & $-4.8909(0.000)$ & $-2.3664(0.009)$ & $-1.5475(0.0609)^{*}$ & $\mathrm{I}(0)$ \\
\hline LnD & $-0.5153(0.3031)$ & $-0.6030(0.2733)$ & $0.1817(0.5721)$ & $-0.4510(0.3260)$ & $\mathrm{I}(1)$ \\
\hline
\end{tabular}

Note: The values in parentheses, (), are the corresponding probability value. ${ }^{* *},{ }^{* *}$, and $*$ represent the significance at levels 1,5 and $10 \%$. Variables are considered as natural logarithm.

According to the results of the Table 4, except for the urbanization rate variable that is stationary at the level, the remaining variables are not stationary at levels and are integrated from the order (1), that is, they become stationary with once differentiation. In the following, the longterm relationship between the research variables is examined by Kao Residual Cointegration Test (1999) [27]. According to Kao Residual co-integration Test (1999), the hypothesis of zero non-cointegration is rejected and the existence of a long-term relationship between researches variables is confirmed (Table 5). In the case of co-integration of variables, one can use the level of variables to estimate the coefficients and avoid false regression.

Table 5. Results of Kao Residual Cointegration Test (1999)

\begin{tabular}{|c|c|c|}
\hline & t- Statistics & Probability-value \\
\hline H0: No Co-Integration & -2.76 & $0.0029 * * *$ \\
\hline
\end{tabular}

Note: $* * * * *$, and $*$ represent the significance at the level 1, 5 and $10 \%$. 


\subsection{Estimation of the experimental model}

Table 6 shows results of the estimation of the research general model by estimating the heterogeneous panel estimator of the mean group of [19]. According to the results of the Kuznets' Hypothesis, the energy intensity is accepted, as the coefficient of variable level of per capita income is positive and the variable coefficient of the least actual per capita income are negative and significant. The urbanization rate coefficient has a negative sign, although it is not statistically significant. The degree of industrialization (the value added share of the industrial sector from the total GDP) has a positive impact on the energy intensity in the countries under investigation and its coefficient is also significant at level 10\%. Given the confirmation of the reversed U-shaped pattern between per capita income and energy intensity among D-8 countries, the per capita income threshold was estimated equal to $\$ 3931.25$.

Table 6. The results of energy intensity Kuznets hypothesis testing by Pesaran \& Smith (1995) Mean Group estimator

\begin{tabular}{|c|c|c|c|c|}
\hline Variables & Coefficients & Standard deviation & z statistics & $\begin{array}{c}\text { Probability value } \\
(\mathbf{P V})\end{array}$ \\
\hline LnY & 4.13 & 2.42 & 1.71 & $0.088^{*}$ \\
\hline $\mathbf{( L n Y )} \mathbf{2}^{\mathbf{L}}$ & -0.25 & 0.12 & -2.01 & $0.044^{* *}$ \\
\hline LnU & -0.77 & 2.01 & -0.38 & 0.704 \\
\hline LnD & 0.14 & 0.08 & 1.69 & $0.09^{*}$ \\
\hline Trend & 0.02 & 0.02 & 1.07 & 0.282 \\
\hline CCons & -13.05 & 13.91 & -0.94 & 0.348 \\
\hline
\end{tabular}

Note: $* * *, * *$, and $*$ represent the significance at the level 1,5 and $10 \%$.

Given to the derivative nature of the energy demand and the fact that demand is different in the short term and long term, the dynamic form of research's general model is estimated in the form of self-regression with panel-distributional delays in the following. In this form, short term and long term coefficients and error-correction coefficients (long-term equilibrium speed) are achievable. The first step is to determine the optimal delay and ARDL pattern form. As seen in Fig. 4, Schwartz's lowest criterion is related to ARDL $(1,1,1,1)$. Therefore, the optimal pattern is ARDL $(1,1,1,1)$.

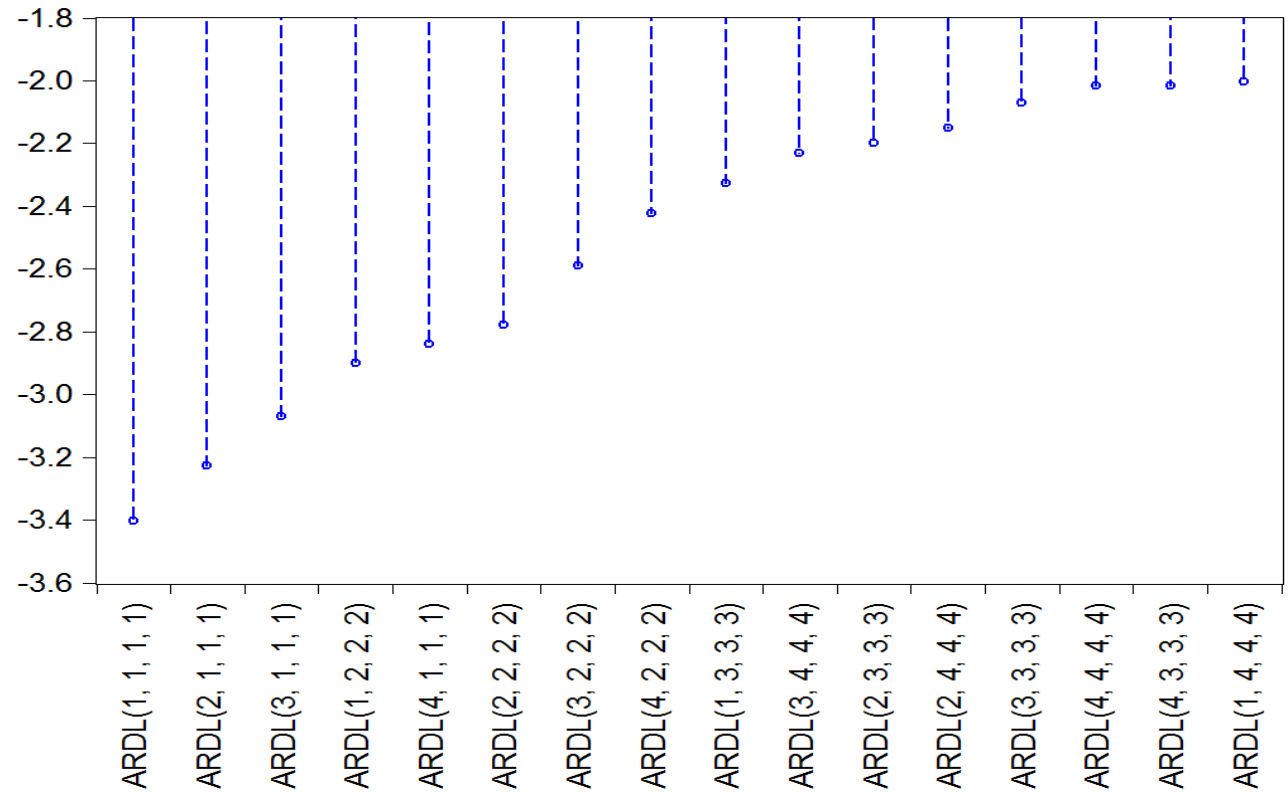

Figure 4. Selection optimal model ARDL according to Schwarz criterion [28] 
Table 7 shows the results of the estimation of the general form of research in the framework of the ARDL $(1,1,1,1)$ pattern. As can be seen, the actual per capita income variable has a negative and significant effect on energy intensity both in the short term and in the long term and reduces it. It is noteworthy that the long term income elasticity is almost double compared to the short- term elasticity, and it can be said that, in the long term, the increase in real per capita income will further reduce the energy intensity of the D-8 countries. Urbanization coefficient is negative in the shortterm (and meaningless), but it is positive in the long term and has a significant effect on the growth of energy intensity in D-8 countries. The inadequate and inappropriate urban infrastructure against the increasing urbanization process in these countries and the improvement of lifestyle (and energy consumption in non-productive sectors) is among the reasons for urbanization's impact on increased energy intensity. The degree of industrialization has a negative and significant effect in the short term and has a positive and significant effect on energy intensity of D-8 countries in the long term.

According to theoretical expectations, the error-correction coefficient sign (ECM) is negative and between zero and 1 and is statistically significant. This means that in the case of a one-percent deviation of long-term equilibrium, 0.26 percent of the deflection is reduced and the coefficients converge to long-run equilibrium in each period. According to the results of the Hausman test, the efficiency of PMG method on MG has been confirmed and null hypothesis is not rejected.

According to the research results, there are many evidences that the economic growth in D-8 countries reduces the energy intensity and GDP energy consuming. Increasing the actual income per capita by upgrading citizens' ability to buy high-energy efficiency products and altering the citizens' mental model about negative effects of energy wasting dissipation will optimize energy consumption and correct energy consumption at micro and macro levels. Therefore, D-8 countries must prioritize their per capita income growth and economic growth.

Table 7. Results of estimating short term and long term coefficients by PMG-ARDL $(1,1,1,1)$ dynamic estimator

\begin{tabular}{|c|c|c|c|c|}
\hline \multirow{4}{*}{$\begin{array}{c}\text { Long-term coefficients } \\
\text { (LR) }\end{array}$} & Variables & Coefficients & z-Statistic & $\begin{array}{c}\text { Probability value } \\
\text { (PV) }\end{array}$ \\
\cline { 2 - 5 } & LnY & $\mathbf{- 0 . 8 6 1}$ & -7.73 & $\mathbf{0 . 0 0 0 * * *}$ \\
\cline { 2 - 5 } & LnU & $\mathbf{0 . 8 6 5}$ & 3.84 & $\mathbf{0 . 0 0 0 * * *}$ \\
\hline \multirow{4}{*}{$\begin{array}{c}\text { Short-term coefficients } \\
\text { (SR) }\end{array}$} & $\mathbf{E C M ( - 1 )}$ & $\mathbf{0 . 5 4 5}$ & 4.14 & $\mathbf{0 . 0 0 0 * * *}$ \\
\cline { 2 - 5 } & $\mathbf{D . L n Y}$ & $\mathbf{- 0 . 2 6 3}$ & -2.86 & $\mathbf{0 . 0 0 4} * * *$ \\
\cline { 2 - 5 } & $\mathbf{D . L n U}$ & $\mathbf{- 2 . 9 3 8}$ & -3.04 & $\mathbf{0 . 0 0 2 * * *}$ \\
\cline { 2 - 5 } & $\mathbf{D . L n D}$ & $\mathbf{- 0 . 1 3 2}$ & -2.46 & $\mathbf{0 . 3 5 1}$ \\
\cline { 2 - 5 } & $\mathbf{C O N S}$ & $\mathbf{1 . 0 5 4}$ & 3.16 & $\mathbf{0 . 0 1 4} * *$ \\
\hline \multirow{2}{*}{ Hausman specification test: $\mathbf{c h i}(\mathbf{3})=\mathbf{5 . 2 1}$ Prob $=\mathbf{0 . 1 5 6 9}$} & & $\mathbf{0 . 0 0 2} * * *$ \\
\hline
\end{tabular}

Source: Findings. Note: $* * *, * *$, and * indicate the significance at the level 1, 5, and 10\%.

\section{Conclusion}

In spite of the fact that the energy intensity which is about GDP energy consuming, countries give important information to researchers and policy-makers, but gives turbulent results for comparison and ranking countries in terms of the level of technical efficiency of energy. In this research, Kuznets' hypothesis of energy intensity and factors affecting energy intensity among D-8 countries during 1990-2014 was examined. For this purpose, static and dynamic mean group estimators with heterogeneous slope coefficients were used.

According to the results, the reversed U-shape pattern was accepted for the relationship between the real per capita income and the energy intensity of D-8 countries, and the per capita 
income threshold was estimated at \$3931.25. According to the ARDL $(1,1,1,1)$ form, income elasticity of energy intensive in the long term is more than short-term, and the increase in actual per capita income will reduce the energy intensity of the countries that are under investigation. Both industrialization and urbanization rates have a positive and significant impact on energy intensity of D-8 countries in the long term and increase the energy consumption in these countries. The great and positive impact of the urbanization rate on energy intensity of D-8 countries suggests the fact that the D-8 have not been able to benefit from urbanization (the effect of agglomeration and scale-saving), perhaps one of the reasons for this effect is inappropriateness and lack of urban infrastructure in these countries against the growing trend of urbanization in these countries. Considering this result, D-8 countries must take energy management in the urban sector seriously and gain from the congestion and scale savings by planning.

\section{References}

[1] Y.Le Pen, B. Sévi, On the non-convergence of energy intensities: evidence from a pair- wise econometric approach, Ecological Economics. 69 (2010) 641-650.

[2] World Bank.2017. Energy intensity level of primary energy (MJ/\$2011 PPP GDP), Sustainable Energy for All (SE4ALL) database from the SE4ALL Global Tracking Framework led jointly by the World Bank, International Energy Agency, and the Energy Sector Management Assistance Program.

[3] P. Mulder, H.L.F. Groot, Structural change and convergence of energy intensity across OECD countries (1970-2005), Energy Economics. 34(6) (2012) 1910-1921.

[4] J. Huang, D. Du, Q. Tao, An analysis of technological factors and energy intensity in China, Energy Policy. 109 (2017) 1-9.

[5] P.K. Adom, Determinants of energy intensity in South Africa: Testing for structural effects in parameters, Energy. 89 (2015) 334-346.

[6] J.W. Burnett, J. Madariaga, The convergence of U.S. state-level energy intensity, Energy Economics. 62 (2017) 357-370.

[7] F. Bilgili et al., The impact of urbanization on energy intensity: Panel data evidence considering cross-sectional dependence and heterogeneity, Energy. 133 (2017) 242-256.

[8] B. Choi, W. Park, B.-K. Yu, Energy intensity and firm growth, Energy Economics. 65 (2017) 399-410.

[9] W.W. Rostow, The Stages of Economic Growth. A Non-Communist Manifesto (3rd Edition), Cambridge University Press, Cambridge, 1990.

[10] G.M. Grossman, A.B. Krueger, Environmental impacts of a North American Free Trade Agreement, National Bureau of Economic Research Working Paper 3914, NBER, Cambridge MA, 1991.

[11] Developing 8 Countries, Accessible from: http://www.developing8.org.

[12] A-M. Seif, Energy intensity: effective factors and estimation of a proposed function, Journal of Energy Economics Studies. 5(18) (2008) 177-201.

[13] M. Jamshidi, An analysis of residential energy intensity in Iran, a system dynamics approach, in: Proceedings of the 26th International Conference of the System Dynamics Society, Athens, Greece, 2008, pp. 20-24.

[14] H. Yu, The influential factors of China's regional energy intensity and its spatial linkages: 1988-2007, Energy Policy. 45 (2012) 583-593. 
[15] P. Sadorsky, Do urbanization and industrialization affect energy intensity in developing countries?, Energy Economics. 37 (2013) 52-59.

[16] H. Yan, Provincial energy intensity in China: The role of urbanization, Energy Policy. 86 (2015) 635-650.

[17] E. Durana, C. Aravenab, R. Aguilarc, Analysis and decomposition of energy consumption in the Chilean industry, Energy Policy. 86 (2015) 552-561.

[18] B.H. Baltagi, Econometric Analysis of Panel Data, 5th Edition, Wiley, 2013.

[19] M.H. Pesaran, R.P. Smith, Estimating long-run relationships from dynamic heterogeneous panels, Journal of Econometrics. 68(1) (1995) 79-113.

[20] M.H. Pesaran, Estimation and inference in large heterogeneous panels with a multifactor error structure, Econometrica. 74(4) (2006) 967-1012.

[21] J. Coakley, A-M. Fuertes, R.P. Smith, Unobserved heterogeneity in panel time series models, Computational Statistics \& Data Analysis. 50(9) (2006) 2361-2380.

[22] M. Eberhardt, T. Francis, Econometrics for Grumblers: A New Look at the Literature on Cross-Country Growth Empirics, Journal of Economic Surveys. 25(1) (2011) 109-155.

[23] M.H. Pesaran, Y. Shin, R. Smith, Pooled mean group estimation of dynamic heterogeneous panels, Journal of the American Statistical Association. 94(446) (1999) 621-634.

[24] E.F. Blackburne III, M.W. Frank, Estimation of nonstationary heterogeneous panels, The Stata Journal. 7(2) (2007) 197-208.

[25] A. Levin, C.-F. Lin, C.-S.J. Chu, Unit root tests in panel data: Asymptotic and finitesample properties, Journal of Econometrics. 108(1) (2002) 1-24.

[26] K.S. Im, M. H. Pesaran, Y. Shin, Testing for unit roots in heterogeneous panels, Journal of Econometrics. 115(1) (2003) 53-74.

[27] C.D. Kao, Spurious regression and residual-based tests for cointegration in panel data, Journal of Econometrics. 90(1) (1999) 1-44.

[28] G.E. Schwarz, Estimating the dimension of a model, Annals of Statistics. 6(2) (1978) 461464. 